\title{
Reshaping exhibition \& museum design through digital technologies: a multimodal approach
}

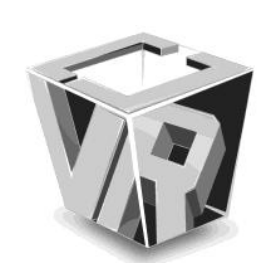

\author{
Marco Borsotti, $\mathrm{PhD}^{1}$ and Letizia Bollini, $\mathrm{PhD}^{2}$ \\ ${ }^{I}$ DPA Architectural Design Department, Milano- Politecnico di Milano \\ ${ }^{2}$ Psycology Department, Milano-Bicocca University
}

\begin{abstract}
Exhibition design as preferential research framework in redefining interior spaces value-ratio in contemporary architecture debate: the merging end integration approach introduced by communication and performative exhibition practices is redesigning culturally and physically the pre-existing spaces.

Exhibition design research innovative carrying out planning approach for changing strategies simultaneity knowledge spreading.

In this way it became the most interesting and topical interior design project act, able to translate performing spaces into crossing experience built also with meanings dissemination and "surfing" knowledge method.

The exhibition design direction is a different tool to control and develop multimodal approach to interior territories whose outcome fit to new social landscapes

The Installation of an exhibition space meaning is now coming into sight as work-in-progress multi-disciplinary range, increasingly complex. The experiential element (whom exponential use of digital solution is just an exterior consequence) will increasing more and more and will bring to ostensive solutions development looking to new classifying parameters capable in enclosing several simultaneous organizing relationships. These parameters represents many super-structural rationalization process aptitudes that draw close true courses and imaginary tours, into complex changeable landscapes where raise to the surface place, objects and viewers sense and myths, made by production act, supervising to thoughts and actions as independent and symbiotic designer and visitor condition.
\end{abstract}

Index Terms - Exhibition, multimodal design, interior design, contemporary architecture

\section{RESEARCH FRAME WORK}

The contemporary exhibition design is a strategic development act for the cultural event, that means to evoke, to inform, to involve perceptually.

It defines an increasingly intertwining relational generating thick behaviour layers, discoveries and reflections, which form its purpose and outcome.

The exhibition design addresses not only the overall level of available works and tracking of routes functional performance, in a continuous reference between conformation space environments control and instruments exhibition definition, but mainly (here it lies the deepest and current meaning) an

Manuscript received on March 5, 2008.

E-mail: marco.borsotti@polimi.it. intensive work of implementation and coordination of different disciplines related to each other, often complementary, applicable into the same scene only by their rules understanding and their mutual interactions intuitions control.

Architecture, design, proxemics, visual design, technology: carrying out an exhibition means to create in its conceptual and executive system the expression of many knowledges that contribute to define possible interpretations of knowledge expression mode.

In this way is taking shape a complete integration profile between multidisciplinary activities connected to the environment, understood as being and becoming and made otherwise accessible as a place through a representative and communicative action.

The contemporary exhibition design establishes an interior space relationship redefinition complex process that takes place with the identification of useful tools to fix and support narrative and performative practices recognized as messages carriers involved, more or less clearly, the object itself of exhibition.

We can define the exhibition design as an polyphonic action project, whose gaze expands into space by redefining the time spent, so that relationships between container host, collected works and visitors defendants are realized in a virtuous convergence where, even through the synchronization of actions and dynamics of movement within the scene outlined, this one becomes a living environment of the narrative meanings represented.

This is mise en scene action based on harmony summary of three significant present together - the place, the object, the man - intended to draw an interference and mutual attractions map which applies in all mental and physical activities interacting in exhibition enjoyment.

The experience, therefore, becomes a key role into the exhibit design configuration, building the exhibition event assemblage process between perceptual awareness and technology knowledge.

From the reasoned deposit (the taxonomic gallery, which meets density criteria, ordered by groups of histories and/or authors), through the absent neutrality (the white cube that chases the spatial disorientation of modern art domain, through the container perceptual removal) [1] and the absent structure (the black box that deals with space cancellation defined by the video-art), the exhibition action definitively move towards multi-modal practical coordination forms, searching for the possible development criteria of interaction interdisciplinary 
subsidiary processes, which transform the empty cavea interior space prepared for a generic entry of objects into a simultaneity of events place [2].

\section{A DIFFERENT FIELD DEFINITION}

"Calculated as service with and on which to build a paradigm series to set the reading work, the installation with his various displaying philosophy has taken as text, linguistic place in which art and architecture occupy a role in social life. Obviously the exhibition conditions of creation are not identical either to art or architecture. For both lives, because the method to show, through the space organization and the visual material composition, must providing a plastic spectacle. However, the displaying articulation, driver of the exhibition itself, is different, so as to constitute in itself a modern opera form, in which the text - visual and spatial - has an important role. [...] The interest in its application goes, however, not to impose it as the only definition, but to recognize it as a ground communication and more precise form of show discipline [3]. We must overcome the many exhibition definitions that are using the most obvious characteristics of temporary and therefore ephemeral project. If indeed provisional and reversibility bonds which characterize an exhibition, makes to implement soft and highly experimental exhibit solutions (Pierluigi Nicolin talk about light architecture) [4] capable of responding to the intense executive compression who deals with the exhibition design, this only may not realize that communication vocation which makes exhibition an essential tool in the recognition process: an issue of identity, which includes orders and makes available the information flow to start off the perceptual discovery, of seeing/revise and remember sequence.

The non-durability of the exhibition and the material-executive transitoriness of its instrumentation, in fact, refers mainly to a technical question, but we can not forget how the discipline of display is primarily a medium of communication.

It is a complex tool to knowledge evolution phenomena transferring which, in its capacity to involve human senses, calls the mind to create new meaning openings, reconciling the two souls who struggle in contemporary man: the sapiens, which interprets the world thanks to his ability to read symbolic, formed mainly around the language-word with which the thought it is drawn up and the videns ones, which has progressively delegated the primacy to images [5]. A match that supports the concepts to the images, into an biunivocal evocation that rather than bring about the first seconds, uses these rather, just to boost the abstraction capacity of the individual and therefore its ability to understand.

The contemporary exhibition design can and must, therefore, represent a virtuous synthesis between reading and watching man: it has to be the communication construction not in opposition, but in constant search of information [6], provided through a multi-sensory issuing apparatus that removes itself from a coercive determination of its content to start, instead, a gradual process of unveiling.

"A [exhibition] project develops and evolves around themes and issues to be communicated and is implemented by means of a smoothly flowing process for supplementing and stratifying the various elements required for its construction, such as light, graphics, images and structures [...]. The aim is then to set the right time and the right distance between the parts, as a sort of distribution grid making it possible to determinate the levels and depths at which the place and its contents may be read." [7] We must definitely say that the contemporary exhibition design finds its current response in being a clever answer to the changing strategies that characterize the distribution of knowledge and culture in the present social landscapes.

The emergence of new mass media - especially television yesterday, the multiple forms of shared communication supported by multimedia technologies today - has radically changed not only how to daily news, especially as the strategies for culture approaching, understanding and exchange, altering its meaning, gradually linked to spectacular and immediacy factors.

These properties emerging quickly moves the knowledge possession and transmission barycentre and new qualities are necessary as a logical consequence: rapid sequences of information, amplification and propagation of surface experiential explorations, uninterrupted movements.

The communication value takes on a new trajectory, rather than focusing the further progressive searching a complete mastery of the subject, as on the speed of new contributions generation, into a continues cross to be nourished by bouncing through the most extensive, planetary, experiences that technological innovation makes available in real time, eliminating the traditional learning expectations.

Sense dynamization is called by Alessandro Baricco. "It like as if the Sense, which for centuries has been linked to an ideal of permanence, solid and complete, had gone to look for a different habitat, dissolving itself into a form that is quite moving structure long journey [...] the knowledge that real counts is which can enter in sequence with all other knowledge $[\ldots]$ the idea that understanding and meaning come to know in depth in what we study, to achieve its essence, is a good idea who is dying: it has been replaced by instinctive conviction that the essence of things is not a point but a path, is not deeply hidden, but dispersed on the surface, does not dwell in things, but hubs outside them, where truly they begin." [8]

We affirm that contemporary exhibition design is a convergence culture project: an attraction motion that involves many theoretical and practical knowledge necessary for the executive fulfilment of a cultural exhibition, as well as those one's each user brings with it at the time of the visit and those, finally, arising from the contemplative fallout.

A confluence that the exhibition design before co-ordinates and then release, making a there and back journey which ranks itself in and from the exhibition planning action as a widespread knowledge instrument.

A participatory planning effort that generates shared culture according to an information flow involving intellectual platforms cooperating with each other. They both belong to the culture vertical depth, as the more traditional sense, and also to the knowledge cross which chases experience fast sequences, immediately shaping into a horizontal connections network 
activated by the charm of the visual, formal and dynamic reports aspects represented in the exhibition mise en scene.

The ability to make and condensing simultaneously two different ways of knowledge access, which in our society are often antagonistic reality, makes the exhibition design an unrivalled planning action, structured as a 'knot passing sequences' [9] that do not exclude, indeed, attract magnetically verticality and horizontality, drawing usability maps of communicative contents providing and suggesting an in-depth analysis and immediately its synthetic connection to others knowledge broadcasters.

\section{MULTIMODAL APPROACH: RESHAPING THE SPACE OF SENSORIAL RELATIONSHIP}

The contemporary exhibition design is of a particular communication medium where 'consumers are encouraged to seek new information and to start up connections between different media contents.' [9] There things you can see clearly, but especially things you can learn by your sense, changes in exploration and understanding resources which can then be shared by exchange ways related to social interactions most appropriate to each visitor.

Digital technologies are increasingly present in the contemporary exhibit world both as a tool in communication media both as objects itself. New perspectives thus open in the field of research into new languages, potentially capable to find a dimension that exploits the potentiality of information science support, not as a simple decantation of a consolidated culture towards a context still to explore (such as the many already diffuse stereotypical products that recall in a reassuring manner the morphemics of similar medias, such as multimedia that reduce the hypertextuality to a banal defoliation of screens) but as original research which experiments with new and adapted expressive solutions.

As Papert [10] remarks, the main characteristic of the computer as a medium is its universality: i.e. the capacity to simulate other media, that is the capacity, in other words, to integrate in a single support more media channels. The computer is a meta-medium that can be seen - rather ambigously - as an instrument and as a mode.

The characteristic of the computer would be that of being a multi-media, as if the co-presence of more channels of communication or of multisensorial reception may imply speaking of diverse media, in other words, of different supporting materials. The reflection of the terminological use of the word medium allows a noticeable change of perspective, implying to outline two poles upon which the research can be oriented: the slope of support instruments, that is of media, and that of languages, or modes of communication.

Then let's not speak so much, or not at all, about multimedia, but rather about a single medium that constitutes an integrated platform between a notational system and other channels of communication, or better: between modalities of communication. Multimodality, then, means to contemporaneously exploit various and complementary channels of communication. This permits an interaction between the digital technologies and the users that mirrors the physical and cognitive richness of the interlocutor human [11].

In fact, also the perception, like the communication, is a cooperative and multimodal process: our senses are not windows, autonomous from the phenomena of the world that is around us, on the contrary, they constitute a collaborative system that allows us to realize a conscious coherence of reality. Similarly, also the semiological activity, as Donald Preziosi sustains, is multimodal because it involves the orchestration of signals originating from a variety of modalities existing together: 'Each such modality or codal system incorporates signatia whose signata comprise signatia in adjacent codes. Such cross-modal indexing, deixis, or linking together of codal components in multimodal activity may thus be seen as correlative to the overlapping of stimuli comprising environmental events across several adjacent sensory systems in perception.' [12] As happens, in example, in the correspondence between the processes of verbal and visual signification, which do not mirror one another according to an exact correspondence, neither can they be considered an equivalent translation of each other. Therefore, the design of the communicative modality must correspond to this complexity of the semiological system, continually busy in the decodification and interpretation of percept, so that the perspetivity channels- auditory, tactile, visual, etc - are aligned in the reception of information that precede from the communicative ambit.

The multimodal approach to the exhibition space \& design becomes then, not the non-exclusive point of view of the project, but the privileged one.

\section{KNOWLEDGE AND SOCIAL LANSCAPE}

It could be argued that the contemporary exhibition design is an integral part of a generation system of collective intelligence [14] which is one of the organization forms, even more valuable because physiologically linked to the diffusion of a high knowledge.

Contemporary exhibition design, to paraphrase Derrick De Kerckhove, could be define 'the practice of multiple intelligences in relation to each other in real-time experience of a project $[\ldots]$ gives immediately people the experience of their intelligence collectively in their group. And it is pleasant to live because it is a new learning experience, or rather: a old cognitive experience which, however, is awareness accelerating and enriching.' [12]

\section{EXHIBITION DESIGN DIRECTION}

Going beyond the idea of exhibition design as a neutral expressive-formal field related to ephemeral, this expertise must be defined by a different category of analytical-formal approach, able to think better of it regulating statute and revise the boundaries and metaphors. This different way of thought look at a complex assembly of a space-time event: an exhibition design production action. In this wider perspective the discipline of displaying takes become a writing operation of a three-dimensional narrative articulated by and for events sequences [13].

These sequences move from objective and symbolic nature of 
exhibited things and by this complex coexistence of telling fragments reconstruct evident linguistic relations and time correspondences, both connections and hidden references, intuited by form assonances or dissonances, mentioned by materials and colors combinations, reveled by lights and shadows immaterial games. The project treats these appearances and assume to made their structure understandable, which ranks it as an instrument to make a different act of looking.

The flow of information dosing and mixing instruments issued by the exhibition must be applied making prior reconnaissance and strict control of both the instrumental actors and their in sync enter and leave the scene (shape and arrangement of exhibition system material entities), both the understanding and manipulation architectural environments host nature and mutants connotations these will take by virtue of the public presence and moving relating to the works shown (crossings, concentrations, dispersions, pause tracking).

"You must capture and combine pieces of facts in sequence, knowing, seeing and hearing exactly what is between them, what kind of contiguity links them with each other." [14] Contemporary exhibition design requires a critical awareness made by a super-structural breath, as a development system designed to sort tools, to recognize timing (of story-telling exposition and revelation) and to compose explicit memory narration (the historical one's of the finds on display) and personnel memory (one's born during the visit and brought back by the memory emotion).

A planning action quite similar to make a movie Building a film that has to tune in to the "time passing of the frame" [15] as evidenced by materials and their meanings careful reconnaissance, immediately transposed into an encoding system that can manifest only live, in time real, by virtue of their presences co-related and confined to the place of action and set by the variable represented by their user.

"Memory of an art-work is related to its continues relocation, to its location through the multitude of sites that host it and the spatialization operating within each individual site. Hence, the importance of an exhibition space far from any abstract idea of neutrality, but, rather, governed by the inevitable presence of a critical act in practice and exposure." [16]

\section{A CONTEMPORARY OVERVIEW}

If the concept of Laurel [18] actually transforms not only in its enunciated theories that the computer is no longer an instrument but a medium, in the same mode, the interactive environments are no longer the passive location of incounters between a spectator and a machine. On the opposite, they are an active system that transforms the use of digital technologies, in an act of sensible experience: that is of jests, actions, behaviours, sensations, conscience, exploration and invention. The exhibit designer has the same material of manipulation as an end goal but the planning takes into account the behaviour of the user "that like an actor one does not know, but looks for his own part and like a spectator reaches out, literally, to put his hands on the scene. The user and contemporaneously, or alternatively, actors and co-authors, the charter of the realization is not that of the show, but maybe that of the invented manifestation of the neo-avant garde, that is called happening [...] in short event planning $[\ldots]$ events of simulation that as they are produce a know how that is not fictitious, but true, they can produce modifications in the state of the world." [19]

The analysis of the metaphor of the scenic representation, according to the multimodal optic of approaches to the use of information tecnologies in exhibition design, has promised us a passage from the concept of surface, according to a graphic and verbalcentric conception of planning, to that of directing an interactive system.

The designer should then be a director that organizes a spatial-temporal discontinuous event via the intertextual screenplay of a multimodal environment, of which the user, integrating, becomes a co-author. The world of the museum and exhibition design is full of examples of this approach in the organization of space and the show already structurally integrated multimodality of interaction between the show - an act of performance - and the users.

Here are some case studies of paradigmatic examples and - even if not exhaustive - of this integrated design approach and communication between architecture that redefines the space itself and the territory of the interior \& exhibition design.

\subsection{Museum Laboratory of the Mind, Rome: Enter Inside Exit Out, 2008. Studio Azzurro, Milan}

In October 2008 at the pavilion 6 of Santa Maria della Pietà Psychiatric Hospital in Rome, has been opened a new guided tour of the Museum of the Mind Lab, designed and produced by Studio Azzurro (Milan). Through the use of new technologies, "Enter Inside Exit Out" offer archival documents, testimonies of lived stories and settings that help understanding the mental diseases complex subject retracing the history of the hospital from its foundation as poor strangers and crazy people hostel to his final closure as mental hospital after about five hundred years of activity.

The entire route has been visually divided by a transparent barrier made by a huge plexiglas reproduction of a wall affected by a patient. Electronic bodies images unceasingly impact against this wall.

During the tour, visitors are continually placed in a position to reflect on the coercive condition containment, being inside or outside of the virtual wall. Moreover, in different environments were placed interactive devices will help understanding perceptual experiences and everyday life of internees, inviting the visitor to immerse themselves in patients life to interact and feel in a magnified way the emotional impact of these places. This first phase of transformation of tour, which involves the ground floor of the building, then offers a path through the memory of the asylum, for a reading of discomfort and diversity, to fight stigma and promote mental health.

Into seven macro-area visitors will cover themes that, by the perceptual experience, bring them to become aware of the internees tragedy experienced, the collective and popular perception of the phenomenon madness, the inner reality representation and the internees point of view. 


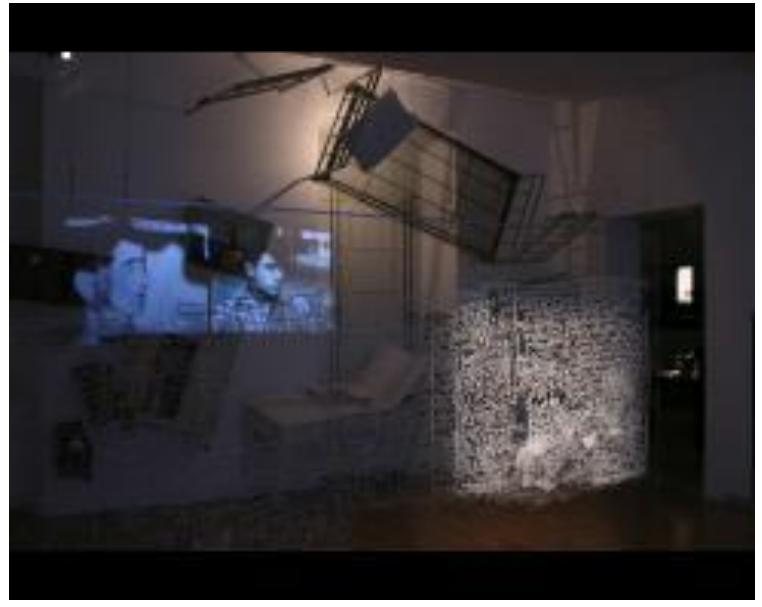

Fig. 1. Museum Laboratory of the Mind, Rome, 2008. Studio Azzurro, MilanFig. 11 shows the modules structure of the server side.

\subsection{De-Viewer, 1991-1992. ART + COM, Berlin}

At the first sight, the visitor is looking towards a traditional oil painting on a wall. With closer inspection, one realises that the painting is deforming at exactly the same place where it is looked at. The viewer's gaze affects the image, which is never seen in the same condition twice. An eye-tracking system analyse the spectator's gaze, from which the exact co-ordinates on the canvas can be calculated. The co-ordinates are then sent to the graphics program that distorts the picture in reaction. The image is reset to its original condition if nobody is looking at it for 30 seconds.

The project was developed as a reaction to the general attitude to computers as tools rather than a medium, still prevalent at the end of the $80 \mathrm{~s}$ and the installation was to promote one of the most crucial qualities of computers as a medium, its interactivity or mutual dialogue.

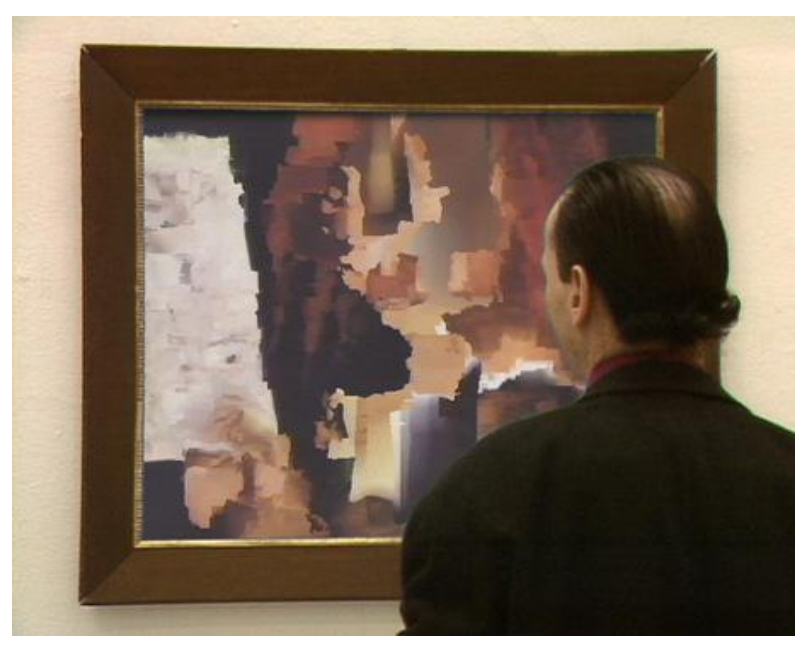

Fig. 2. De-Viewer, 1991-1992. ART + COM, Berlin .

\subsection{BMW Museum, 2008. ART+COM, Berlin}

BMW Museum is a museum of mobility, so the challenge was to create a dynamic environment for this place. The approach was to transform the surface of the building into a mediatecture, based on the means with the highest dynamic impact on human perception: the moving image.

So seven hundred square meters of the walls are completely covered with monochrome white LEDs. The then faced with opaque glass. With this, no technology is visible any more, and the regular glass façade elements are in the foreground. This mediatecture, on one hand, enlarges the space by extending it virtually through three-dimensional moving images. It also sets the exhibited parked cars into motion relative to the animated walls. The moving reflections of the mediatecture on the cars are an additional movement, making the cars drive. In conjunction with a video-tracking system, this mediatecture can be switched to reactive mode, in which the pattern of illumination changes according to the mere presence of visitors and thus actively involves them in the scenario.

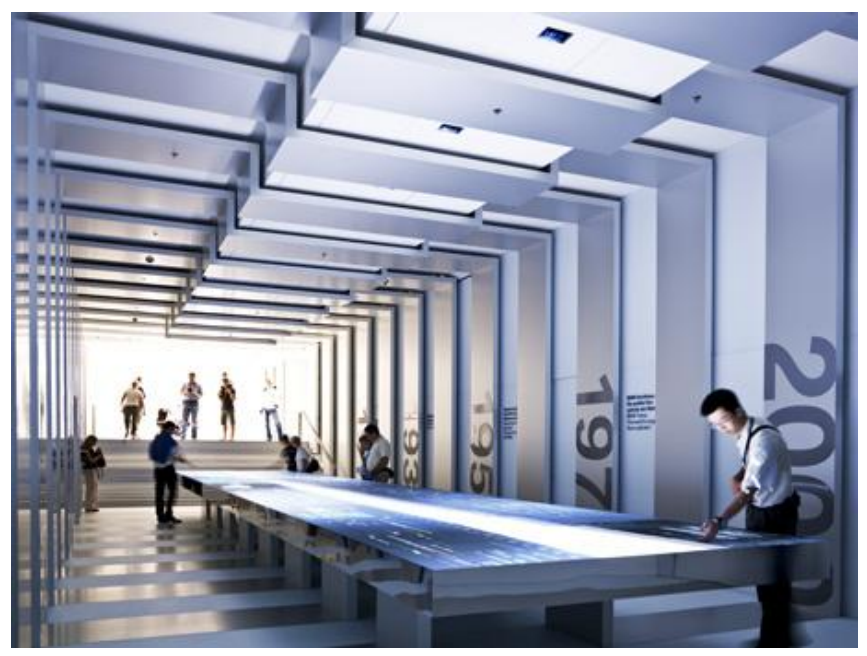

Fig. 3. BMW Museum, 2008. ART+COM, Berlin

\subsection{Numbers Berlin \& Taiwan Taiwan 2004-2005. ART + COM, Berlin}

Numbers are commonly seen as quantitative measures of entities. Depending on the context however, they often also have religious, historical, mathematical and philosophical meanings. Floating.Numbers attempts to bring back this often forgotten or unknown layer of meaning into their interpretation in the age of digital determinism.

Floating.Numbers is a 9x2 meter interactive table on which a continuous stream of numbers is floating. Individual digits appear randomly at the surface and, once touched by a visitor, reveal their meaning in text, pictures, animation and small interactive applications.

The table is consciously employed as an interface: the visitors are engaged into a dialog with the application as well as with other visitors about the numbers they explore. On the underside of the tabletop a grid of in-house developed capacitive sensors are installed detecting the position of the visitors' hands through the wood. All numbers floating on the table are so-called typobots (type-robots) with specific behaviour (move along different currents; move forward, swishing like a fish depending on their length; move in the direction of attractors; etc.). The goal was to offer an autonomous system giving users 
the impression they are engaged with an independently acting and non-deterministic system.

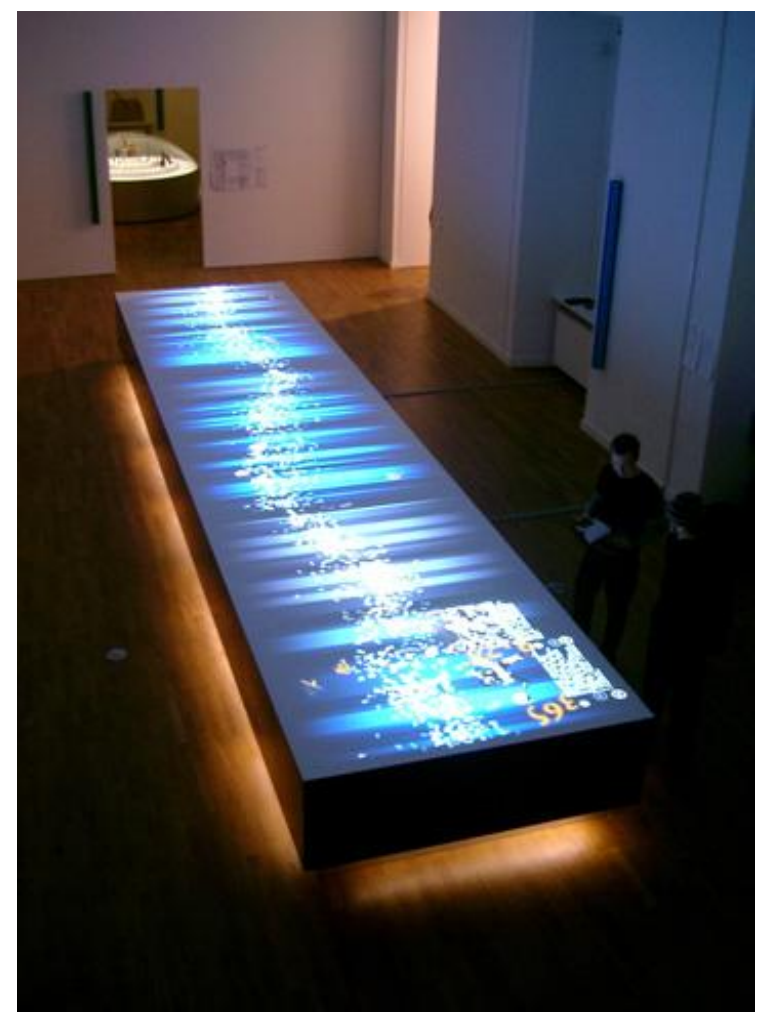

Fig. 4. Floating.Numbers, Berlin \& Taiwan Taiwan 2004-2005. ART + COM, Berlin

\subsection{Generation Random, 20}

For his ten-year chart the graphic office Lust, organized an exhibition called Random Generation presenting a project that aims to act as a visual interactive catalogue, where information physically stored can trigger digital information. Supporting on a digital table, a box containing a RFID2, on table display are shown images and other multimedia content, through which you can then interact touch. The metaphor used is that of traditional archiving, but the navigation and use of the material happens on a multi-touch screen, and then, through a direct manipulation symbolism and real-world actions are mixed. Lust says about its intention: "Now anyone can be a distribution and consumption of information hub. The role editor is no longer in the old hierarchical information structures but in the hands of consumers. Today the designers' task is to create the conditions and parameters and give the reader the freedom to react and add. Marshall McLuhan once said that the medium is the message, but now we can say that the content is the medium".

\section{CONCLUSION}

The challenge for the exhibition design direction approach is to find a new grammar and syntax to synthesize the different communication modalities.
The exhibition space meaning installation is now coming into sight as work-in-progress multi-disciplinary range, increasingly complex. The experiential element (whom exponential use of digital solution is just an exterior consequence) will increasing more and more and will bring to ostensive solutions development looking to new classifying parameters capable in enclosing several simultaneous organizing relationships. These parameters, defining innovative outlines that assimilate theoretical exhibition space to multiple real visiting experience (from narrative emotional sequence, performative path and virtual created experience till more urban-oriented type), represents many super-structural rationalization process aptitudes that draw close true courses and imaginary tours, into complex changeable landscapes where raise to the surface place, objects and viewers sense and myths, made by production act, supervising to thoughts and actions as independent and symbiotic designer and visitor condition.

\section{REFERENCES}

[1] O'Doherty, Brian. Inside the White Cube: the ideology of the gallery space. Santa Monica CA: Lapis Press, 1986.

[2] Bollini, Letizia. "MUI: design of the HC Interfaces as a directing of communications modes targeted on human senses" in Senses and Sensibility in Technology, Conference proceeding, IADE, Lisbona, pp. 182-186, 2003.

[3] Celant, Germano. Artmix. Flussi tra arte, architettura, cinema, design, moda, musica e televisione. Milano: Feltrinelli editore, 2008.

[4] Nicolin, Pierluigi. Cos'è questo, l'architettura, in Lotus International 115, pp. 30-35, 2002.

[5] Sartori, Giovanni. Homo videns. Televisione e post pensiero. Roma-Bari: Laterza \& Figli, 1997.

[6] Perniola, Mario. Contro la comunicazione. Torino: Giulio Einaudi editore, 2004.

[7] Migliore, Ico \& Servetto, Mara. Space Morphing. Migliore+Servetto temporary architecture. Milano: 5 Continents Editions, 2007.

[8] Baricco, Alessandro. I barbari. Saggio sulla mutazione. Milano: Feltrinelli editore, 2008.

[9] Jenkins, Henry. Convergence culture. New York: New York University Press, 2006.

[10] Papert, Seymour. Mindstorms: Children, Computers and Powerful Ideas. Basic Book, New York, 1980.

[11] Bollini, Letizia. Registica Multimodale: il design dei New Media, Libreria CLUP, Milano, 2004.

[12] Preziosi, Donald, Advantages and limitations of visual communication. In Visuelle Kommunication und/oder verbalekommunication? Krampen, M. (Ed.) Georg Holm Verlag, Hildesheim, 1983: 25-35.

[13] Lévy, Pierre. L'intelligenza collettiva. Per un'antropologia del cyberspazio, Milano: Feltrinelli editore, 1994.

[14] Mediartech, Firenze. "Derrick De Kerckhove/Pierre Levy, "Due filosofi a confronto. Intelligenza collettiva e intelligenza connettiva: alcune riflessioni", Mediartech.

Htpp://www.mediamente.rai.it/home/bibliote/Intervis/d/dekerc05.htm (accessed March 27, 1998).

[15] Borsotti, Marco. "The exhibit design prodution", in Places \& themes of interiors. Contemporary research worldwide, edited by Luca B. Peressut, Imma Forino, Gennaro Postigione, Francesco Scullica. Milano: Interiors Studies - Franco Angeli, 2008.

[16] Tarkovskij, Andrej. Scolpire il tempo. Milano: Ubulibri, 1997.

[17] Ferrari, Federico. Lo spazio critico. Note per una decostruzione dell'istituzione museale. Roma: Luca Sossella editore, 2004

[18] Laurel, Brenda. Computer as a theatre. Addison and Wesley, New York, 1984.

[19] Bollini, Letizia, Multimodalità vs.multimedialità, in Il Verri, n. 16, maggio 2001: 144-148. 


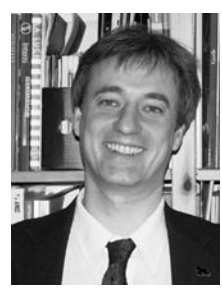

Marco Borsotti (marco.borsotti@polimi.it), received the Architecture degree in 1991 and Ph.D. degree in Interior Architecture \& Exhibit design in 2000 from the Architecture Faculty of Politecnico of Milan. Currently, is Architectural Design Studies Lecturer at Architettura e società Faculty of Politecnico of Milan and Exhibit design (Interior design Studies) Lecturer at Design Faculty of Politecnico of Milan. He takes part in Interior \& Exhibit design field research activity of DPA-Architectural Design Studies Departement of Politecnico of Milan. His research interests include Interior design, Exhibit design, Product design and Architectural Design and he takes part in conferences, exhibition and award organization and attendance.

$\mathrm{He}$ is Frate Sole Foundation - International Sacred and European Architecture Award guest referee and Editorial staff board member of Italian architectural and arts review Anfione e Zeto.

Articles, essays and projects have been published by specialized review; most recent publication book is "il progetto di allestimento e la sua officina" (Exhibition design and its workshop), Milan, Skira, 2009.

In 2000 establish mabo44 architecture \& product design where professional experiences are linked to theoretical and methodological research and teaching methodology.

About most recent completed projects: Castle Belvedere Tower, Castello, Castel D'Ario, (Mantua, Italy) and Truffle Museum, Borgofranco Po (Mantua, Italy).

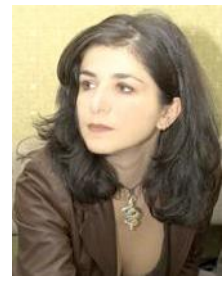

Letizia Bollini, PhD (letizia.bollini@unimib.it) Dr. Letizia Bollini holds a degree in Architecture and a Doctorate in Industrial Design and Multimedia Communication from Politecnico di Milano.

Since 1995 she has been involved with web interface design, multimedia publishing and visual design. She is active as professional consultant, theoretical and methodological researcher, teacher and editor. She published in leading journals and attended international workshops and conferences. Academic experience includes appointments as a teacher at Politecnico di Milano and Bologna University, consultant with Consorzio Nettuno (Italian Ministry for the Education); Tv lecturer for the "e-learning for the Web Design"; visiting scholarship at San Francisco State University. At present she is assistant professor at Communication \& Psycology and Theory and Technology of Communication, Università degli Studi Milano Bicocca.

Since 1999 she has been General Secretary of the AIAP - Italian Association for Visual Design; confirmed as National Board Member in 2002 and 2005 and Italian Representative at ICOGRADA - International Council of Graphic Design Associations. Principal research interests are MUI, Multimodal directing, information architecture and visual design for new-media.

Note: although the paper is a result of the joint work of both authors, Marco Borsotti is in particular author of parts I, II, IV, and V, and Letizia Bollini is author of part III, VI and VII. 